\title{
䙚CONSTRUÇÃO DO CORPO: IMPLICAÇÕES EM UM CASO DE PSICOSE INFANTIL
}

\author{
Marcella Monteiro de Souza e Silva
}

ste trabalho nasceu de uma indagação com a qual me vi defrontada em minha experiência clínica. Desde meus primeiros contatos com meu paciente $^{1}$, a relação que ele estabelecia com seu corpo me intrigava; era frequente a ausência de qualquer referência à dor quando se machucava; parecia procurar limites para o próprio corpo fora dele, nas paredes e na lousa. Esta experiência me suscitou curiosidade e interesse em pesquisar o modo pelo qual se dá a constituição psíquica do corpo em geral e, mais especificamente, na patologia da psicose.

Esta reflexão, tomada sob uma perspectiva psicanalítica, colocou-me de imediato algumas questões preliminares sobre o meu objeto: primeiramente, de que corpo se trata? E, ainda, como se dá a constituição psíquica do corpo no sujeito?

Não pretendo, no âmbito deste artigo, responder a estas questões de forma a esgotá-las; meu esforço será apenas no sentido de indicar algumas possibilidades de pensarmos sobre as possiveis falhas ocorridas nesse processo que acarretam a vivência desintegrada e fragmentada do próprio corpo que observamos em pacientes psicóticos. E, quem sabe, compartilhar um pouco de alguns momentos clínicos que tive a oportunidade de vivenciar durante este atendimento.

\section{FUNDAMENTAÇÃO TEÓRICA}

Foi Freud quem primeiro abriu o caminho para pensar o corpo além da sua dimensão física e biológica, introduzindo seu aspecto psicossexual. É nos Três Ensaios Sobre a Sexualidade (1974b) que Freud, distanciando-se das teorias vigentes na época acerca da sexualidade, cujo conceito privilegiado era o instinto, introduz um novo modo de pensar a sexualidade através da noção de pulsão.

$\mathrm{Na}$ sexualidade humana, aponta Freud, não se trata mais de instinto conduta cujos padrões são fixados hereditariamente, e sim de pulsão - uma pressão, ou força que tem sua fonte em 
uma excitação corporal (estado de tensão) e que impõe uma exigência de trabalho ao aparelho psíquico ${ }^{2}$. Na medida em que a psicanálise não toma como ponto de partida para sua teoria o instinto, ela rompe também com o corpo biológico. Não se trata de conceber o corpo como um dado, uma totalidade organizada, composta de partes com seus limites definidos e comandados pelo instinto. Trata-se, antes, de um corpo pulsional que deverá ser construído a partir do trabalho psíquico exigido pelas pulsões e pela história de satisfações e frustrações delas provenientes. Assim, a ordem natural é, no homem, suplantada pela ordem simbólica no que diz respeito à constituição do corpo.

No que diz respeito a nossa segunda questão, qual seja, o modo como se processa a constituição psíquica do corpo, privilegiarei as contribuições de Françoise Dolto, dada sua constante curiosidade e reflexão sobre as falhas ocorridas neste processo, bem como sua vasta experiência na clínica da psicose infantil.

Dolto propõe dois conceitos fundamentais para pensarmos a constituição do corpo: a imagem do corpo e o esquema corporal. O termo "imagem", forjado por Dolto, deve ser diferenciado do conceito lacaniano de imagem especular na medida em que não se trata da imagem devolvida pelo olhar do outro, mas sim de uma imagem inconsciente, substrato relacional da linguagem. Ela é definida como: "a síntese viva de nossas experiências emocionais: inter-humanas, repetitivamente vividas através das sensações erógenas eletivas, arcaicas ou atuais (...) é a encarnação simbólica inconsciente do sujeito desejante." (Dolto, 1991, p.14). Apesar de "imagem", não se reduz ao visível incluindo também o audivel e o sensível, Dolto refere-se à imagem respiratória, olfativa e tátil.
A imagem do corpo é desde sempre peculiar a cada um e eminentemente inconsciente, não se estrutura pela aprendizagem e sim "pela comunicação entre dois sujeitos e o vestígio, no diaa-dia, memorizado, do gozar frustrado, reprimido ou proibido (castração no sentido psicanalítico, do desejo na realidade)" (Ibid, p.15).

O esquema corporal, ao contrário, faz referência a uma realidade de fato, ou seja, ao nosso viver físico, carnal, enquanto participantes de um mundo também físico. Ele é de saída o mesmo para todos os indivíduos, mas sua estruturação futura dependerá da aprendizagem e experiência pelas quais atravessam o indivíduo. Neste sentido é em parte inconsciente, mas também préconsciente e consciente.

O cruzamento do esquema corporal e da imagem do corpo, graças ao qual podemos habitar o mundo, se dá na medida em que é o esquema corporal que permite a objetivação desta intersubjetividade que é a imagem do corpo. É neste sentido que Dolto coloca como função do esquema corporal interpretar a imagem do corpo. No entanto esta interpretação não é necessariamente passiva, resultando em uma relação nem sempre de coincidência entre a imagem do corpo e o esquema corporal. Por exemplo, um esquema corporal atingido, mediador entre o sujeito e o mundo, pode comportar uma imagem de corpo saudável. É o caso de crianças acometidas por doenças precoces, tais como a poliomielite que deixa seqüelas no esquema corporal. A enfermidade pode não afetar a imagem do corpo, caso a relação da criança com sua mãe e com o ambiente humano tenham permanecido bastante satisfatórias no sentido de poder conter a angústia da criança, sem sucumbir a ela, mas antes, fornecendo-lhe um espaço onde possa ser elaborada. Nesse 
processo de elaboração, é capital que a criança possa, pela linguagem mímica e verbal, expressar seus desejos e fantasias (sejam eles passíveis de realização ou não) quanto a seu esquema corporal doente. Assim, ao falar para a mãe sobre atividades que desejaria realizar, tais como correr, pular, nadar, ela projeta uma imagem íntegra do corpo, simbolizada pela palavra, em fantasias de satisfação erótica. Na medida em que a mãe pode receber e reconhecer estes desejos, mesmo ciente de sua impossibilidade de realização efetiva, ela capacita a criança a integrá-los na sua linguagem de comunicação inter-humana. Aqui temos um vislumbre da importância da linguagem na construção da imagem do corpo e na intersecção dessa com o esquema corporal.

O que vimos, portanto, segundo a concepção de Dolto, é que, apesar do cruzamento entre imagem do corpo e esquema corporal, a estruturação de ambos percorre caminhos diferentes. Que caminhos seriam estes?

a) Esquema corporal: lugar da necessidade

$\mathrm{O}$ esquema corporal inaugura-se no momento do nascimento e se desenvolverá como um corpo real, submetido a leis da fisiologia. Ele é desde sempre uma realidade de fato, lugar e fonte das pulsões.

b) Imagem inconsciente do corpo: lugar do desejo

A imagem inconsciente do corpo se constitui, inicialmente, em referência às experiências olfativas, visuais, auditivas e táteis que a criança vivencia, em carácter de comunicação, com sua mãe. Tais experiências se constituem enquanto marcas no desenvolvimento libidinal da criança.

Sabemos que o desenvolvimento psicossexual da criança se dá não apenas em função do desenrolar de um programa fisiológico pré-determinado, mas é estruturado, prioritariamente, em função das relações que ela estabelece com o mundo e seus outros significativos. Este desenvolvimento se caracteriza pela prevalência, eletividade das zonas erógenas que vão se deslocando no decorrer do processo. A imagem do corpo será, portanto, dependente da fase de seu desenvolvimento. A criança cuja imagem do corpo é a do estágio oral compreenderá as palavras de prazer e desprazer relacionadas com o funcionamento e a erótica oral. $\mathrm{O}$ célebre caso "A criancinha com a boca de mão" (Dolto, 1991, p.18), exemplifica não só essa interdependência da imagem do corpo com a fase do desenvolvimento libidinal, mas também a intrincação pulsional em jogo na relação da imagem do corpo com o esquema corporal. Trata-se de uma menina que, embora dona de um esquema corporal intacto, não podia mais fazer uso de suas mãos e braços, que permaneciam constantemente inertes, colados a seu tronco. Essa criança encontrava-se no estágio oral do desenvolvimento libidinal e, como sabemos, nesse estágio, a criança estende o oral em todo o seu contato com o mundo: são as mãos que, ao modo de uma boca, sabem pegar, largar ou falar. Foi pensando nisto que Dolto a convida a pegar uma massinha de modelar dizendo: "você pode pegar com a sua boca de mão". Em seguida a menina pega a massa de modelar com sua mão levando-a à boca. A intervenção da analista com as palavras: "pegue com sua boca de mão" provocou uma união entre a boca e a mão da criança, de modo que, de posse de uma "boca na mão" ela pôde fazer uso da potencialidade de seu esquema corporal (agora em consonância com a sua imagem do corpo).

Uma vez que a imagem do corpo está ao lado do desejo, sendo, portanto, uma "montagem", que se dá no desen- 
volvimento e deslocamento das zonas erógenas segundo a relação com o outro, ela é o representante das pulsões e, por isto, envolve uma elaboração constante. Chegamos aqui à importância, para a construção da imagem do corpo, das castrações pelas quais passa o sujeito.

Dolto caracteriza a palavra castração em psicanálise como "um processo que se realiza em um ser humano quando outro ser hunano lhe significa que a realização de seu desejo, sob a forma que gostaria de lhe conceder, é proibida pela Lei. Este significado passa pela linguagem, seja ela gestual, mímica ou verbal". (Ibid, p.62) A imposição da Lei, secundariamente, favorece um trabalho de recalcamento das pulsões que sofrem então um remanejamento dinâmico, e o desejo, cujo alvo inicialmente visado fora proibido, procura outros meios de dealização: as sublimações. Tais meios exigem, portanto, um processo de elaboração, ou seja, de simbolização, que o objeto inicialmente visado não exigia. É para sinalizar o potencial simbolizador, portanto humanizador deste processo, que Dolto acrescenta o adjetivo "simbolígeno" à palavra castração. Assim a castração, como aponta Nasio (1991, p.29), "é elevada à categoria de uma operação geradora de efeitos positivos e socialmente humanizantes para o corpo da criança", pois, na medida em que é uma proibição a satisfação imediata, anteriormente conhecida no corpo-a-corpo com a mãe, contribui para a elaboração da imagem do corpo que justamente se estrutura em função das emoções dolorosas vividas frente ao desejo proibido.

Existem, no entanto, duas condições para assegurar a dimensão simbolígena da castração: Em primeiro lugar, é necessário um momento certo para ocorrer cada castração; momento esse em que "as pulsões, as que estão em curso, trouxeram um certo desenvolvimento do esquema corporal, que torna a criança capaz de arranjar seus prazeres de outra maneira que não na satisfação total do corpo-a-corpo.." (Ibid, p.69).

Em segundo lugar, é importante que o adulto de quèm provém a interdição esteja, ele mesmo, marcado por essa proibição, podendo, então, auxiliar a criança a superar essa prova na medida em que se constitui como um modelo identificatório para ela de um adulto que, atravessado pela castração, ainda obtém prazer. Essa confiança no adulto interditor e a esperança de que o prazer proibido neste momento não é o único possível, são fundamentais para a castração obter um resultado simbolígeno.

A castraçâo umbilical, a primeira mencionada por Dolto, é a que se refere à perda de percepções intra-uterinas conhecidas, e o aparecimento de percepções novas como a respiração aérea, a sensação da massa corpórea submetida à gravidade, a manipulação de seu corpo pelos outros e a percepção da luz e de vozes.

A castraçâo oral, condensada no episódio do desmame, na medida em que separa a boca da criança do seio aleitador materno, interditando o contato mucosa à mucosa, impõe uma ruptura 
no contato corpo-a-corpo através do qual a criança se encontrava totalmente dependente da presença materna. Tal ruptura traz a necesssidade de uma nova maneira de ser frente a um desejo, cuja satisfação, anteriormente conhecida, tornou-se impossível.

Podemos dizer que o desmame é vivido como uma castração recíproca da mãe e do bebê: a partir da separação corporal, o par mãe-bebê deverá encontrar outros recursos para a comunicação e intercâmbio de prazer à distância do corpo-a-corpo, em uma comunicação verbal e gestual. Na ocasião da perda do seio, no entanto, permanecem trocas sutis com a mãe: o tato, o odor, o corpo-a-corpo no momento da mamadeira. É essa comunicação - não mais reduzida a imediatez do corpo-a-corpo, mas sim estendida à erogeneização do olfato, audição e visão - que confere o caráter "simbolígeno" à castração oral. Aqui temos a oportunidade de constatar com nitidez a importância da linguagem verbal no intercâmbio mãe - criança. Quando a mãe dá assistência ao filho, falando com ele sobre suas necessidades, satisfações e insatisfações (referidas a zonas erógenas) ela está "humanizando" a angústia difusa sentida por ele através de palavras. Essas palavras proferidas pela mãe durante suas trocas com a criança - de leite, fezes, cheiro, calor - funcionam como mediadoras dessa relação mãe e filho e deste com suas próprias zonas erógenas, possibilitando à criança construir e reelaborar constantemente sua imagem de corpo olfativa, tátil, oral e anal.

A castração anal, que ocorre geralmente por volta de vinte e quatro a vinte e oito meses, refere-se a duas etapas. A primeira delas é a aquisição pela criança de uma certa autonomia no sentido que, capaz agora de motricidade ágil e voluntária, separa-se da assistência motora completa da mãe. Essa aqui- sição deve ser compreendida como um processo que tem origem na aquisição do controle dos esfincteres, primeira motricidade agradável para si e para sua mãe, que vem limpá-la e levar aquilo que ela produziu. A segunda diz respeito à proibição que é dirigida à criança frente ao perigo de ela prejudicar, com seus atos motores descontrolados, tanto o seu próprio corpo quanto o mundo animado e inanimado que a rodeia.

Na castração do espelbo, Dolto desenvolve uma concepção largamente original da função do espelho na constituição da imagem inconsciente do corpo, elevando esta experiência vivida pela criança em ver sua imagem refletida no' espelho, à categoria da quarta castração pela qual atravessa o sujeito. Poderíamos dizer que a diferença fundamental da experiência do espelho, tal como a lê Lacan e tal como a desenvolve Dolto, reside justamentalmente na natureza deste corpo que sofre o impacto do espelho.

Para Lacan o estágio do espelho é uma experiência inaugural e primeira na medida em que envia à criança uma imagem de totalidade e integração contrastante com sua vivência corporal de dispersão e fragmentação. Assim, o estágio do espelho de Lacan marca o início de uma vivência, mesmo que imaginária, de um corpo globalizante, daí a sensação de "júbilo" da criança face a sua imagem.

Contrariamente, para Dolto, o corpo que sofre o impacto do espelho não é um corpo despedaçado e fragmentado e sim um corpo coeso e contínuo. "A criança se sente coesa desde antes do estágio do espelho, graças às referências viscerais: por exemplo, as sutis sensações peristáticas contínuas de seu tubo digestivo, no qual ela sente o itinerário do objeto parcial oral, (...) mais tarde, percebe o trânsito abdomi- 
nal (...) em seguida,é o objeto parcial anal e sua expulsão que a situam em relação às suas sensações táteis e olfativas específicas. Tudo isto constitui um continuum coeso, interno, limitado ao conjunto de seu revestimento cutâneo, que sensações táteis delimitaram na ocasião dos cuidados maternos e do regaço." (Ibid, p.129) Assim, ao invés da - sensação de "júbilo" a criança entristece face à constatação da diferença que a separa de sua própria imagem, ela facilmente imagina ser um carro, um avião, um cachorro, um pásssaro. Como constata Dolto, "a partir da experiência do espelho, não será mais como antes. Ela (a criança) sabe que não pode mais se confundir com uma imagem fantasmática de si mesma, que não pode mais brincar de ser o outro que falta a seu desejo".(Ibid, p.126)

A imagem inconsciente do corpo será, então, recalcada pela imagem do espelho

- a imagem de si conhecida no espelho- reaparecendo eventualmente em sonhos, recorrentemente em afecções psicossomáticas ou ainda onipresentemente nas crises psicóticas.

Dolto, ao qualificar esta experiência do espelho como uma ferida, "esta ferida irremediável da experiência do espelho, pode-se chamá-la de buraco simbólico do qual goteja, para nós todos, a inadaptação da imagem do corpo e do esquema corporal" (Ibid, p.151) atenta para a importância do olhar do outro na constituição da criança. Uma vez marcada por esta ferida, a criança, a fim de assegurar-se e defender sua identidade, torna-se alerta à imagem de seu ser devolvida pelo olhar do outro em relação com ela.

A castração genital não edipiana, por volta dos 30 meses, é a descoberta da diferença sexual. Ela é herdeira da experiência do espelho na qual a criança supostamente apropriou-se de seu corpo reconhecendo seu rosto, o seu nome e sexo, podendo, agora, fazer a distinção de seu corpo com outros corpos e constatar suas limitações.

A castraçâo genital edipiana: depois de constatada a diferença sexual, introduz a criança no entendimento da relação triangular e do complexo de Édipo, conduzindo-a à castração secundária. Esta refere-se à proibição do incesto que libera e impulsiona o desejo para fora do meio familiar.

O caso de Renato, do qual destacarei alguns fragmentos clínicos, nos incita a pensar mais detidamente nos possiveis entraves ocorridos nas primeiras castrações que o impediram de experimentar as posteriores.

\section{DISCUSSÃO DO CASO}

Lúcia traz seu filho único, de seis anos, ao Lugar de Vida, relatando uma vasta história de passagem por outras instituições e com um diagnóstico final do Hospital das Clínicas de síndrome autística e psicose simbiótica. Sua queixa principal no momento em que procura o Lugar de Vida reside no fato de Renato "não falar".

Em nossas primeiras entrevistas, Lúcia conta de sua gravidez: "eu só fiquei tão nervosa assim quando eu fiquei grávida do Renato. Era horrivel, eu tinha que colocar pano na minha boca para eu não vomitar, e só quando todo mundo ia embora de casa eu corria para o banheiro e vomitava. (..) Ele (João, o marido) tanto fez que conseguiu fazer o Renato. Foi da primeira vez, eu não queria fazer "coisa" com ele. Eu não sabia o que fazer, pensei em assumir sozinha, em tirar... Uma outra vez fui para a casa dele e ele ficou me forçando a fazer "coisa" com ele. Eu não queria porque os pais dele 
iam chegar, aí ele começou a me xingar e a me bater e aí eu saí correndo."

A imagem corporal de Renato é construída a partir do desejo de Lúcia, que deveria ser capaz de reconhecê-lo como um corpo imaginado, fantasiado desde os primórdios da gravidez. Como nos aponta Aulagnier, a relação mãe-filho pré-existe ao parto e o modo como a mãe investe sua libido na imagem deste filho é determinante para esta relação. Ela deve ser capaz de "imaginar" um corpo já completo e unificado, passível de investimento libidinal enquanto corpo separado desde o início da gravidez e não tomá-lo como o que de fato é: um embrião em desenvolvimento. Na ausência do "corpo imaginado", "assistimos não a um desinvestimento do narcisismo em favor da futura criança, mas a um sobreinvestimento narcisista daquilo que é sentido como uma produção endógena, como algo que vem acrescentar-se ao corpo próprio (...) O corpo real da criança não terá outro reconhecimento, nem outra razão de ser, senão permanecer testemunha da existência e onipotência materna." (Aulagnier, 1990, p.19) Em algumas sessões com Lúcia me parece que ela justamente "falha" nesta tarefa de imaginar este "ser"; conta também que "não sentiu nada" quando, desde o hospital, Renato recusava-se a pegar o seu seio. "Eu não sentia nada pois não conhecia nada de bebê, só não entendia o que se passava".

Renato é tomado como um bebê, que necessita de todos os cuidados físicos básicos e deve ser alimentado incessantemente. Ele chegava, no início do tratamento, com um pacote de bolacha na mão e muitas vezes com a boca cheia de comida sem engoli-la. $\mathrm{Na}$ ausência de alimento, Renato coloca papel na boca e assim permanece por muito tempo.

As contribuições de Winnicott e posteriores desenvolvimentos de Dolto acerca do conceito de objeto transicional, nos permitem pensar que a bolacha, para Renato, funciona como um objeto transicional na medida em que representa, alude à sua relação rememorada com um adulto assegurador, sua mãe. Como demostra Dolto, a necessidade do objeto transicional pode ser entendida em função da ausência de suficientes palavras proferidas pela mãe que fizessem a mediação entre o desejo da criança e seu objeto ausente. Sua idéia é de que a mãe, através da palavra, na medida em que fala ao filho sobre aquilo que ele desejaria, mas não lhe dá ( como "você quer mamar mas agora não é hora"), mediatiza a ausência de um objeto ou a não satisfação de uma demanda de prazer, validando, pelo próprio fato de falar disto, aquele desejo insatisfeito. Deste modo, a criança que manteve uma relação com a mãe povoada de palavras alusivas a seus desejos, face a um perigo iminente de separação do lugar de segurança materna, encontra palavras que, funcionando como "objetos transicionais sonoros", podem trazer, simbolicamente, seu objeto de desejo primordial, a mãe ausente. 
O objeto transicional para Dolto, seria, nesse sentido, uma "linguagem materializada", ou seja, na ausência dessas palavras da mãe que pudessem validar o desejo insatisfeito da criança, algo concreto é convocado. ${ }^{3}$ Resta-nos indagar por que a comida é o objeto eleito como transicional. Tomemos as palavras de Lúcia referentes à amamentação de Renato: "o sol ia e se punha e eu com o Renato no peito sentada na cama olhando pela janela ...ele mordia o peito até sangrar e mamar sangue", palavras essas sugestivas de uma amamentação ininterrupta que parecia ocupar Lúcia inteira e exclusivamente nesta atividade. É de nosso conhecimento que o contato corpo-a-corpo de uma mãe com seu filho é necessário e erotizante para ambos, mas, retomando a questão da castração oral mencionada anteriormente, faz-se necessário que o desmame venha justamente marcar uma separação nessa relação corporal e que introduza uma etapa diferente de intercâmbio de prazer, permitindo à criança descobrir novas maneiras de comunicação, ou seja, de trocas, com o exterior. Neste sentido podemos aventar a hipótese de que a excessiva erogeneizacão da boca de Renato esteja articulada com uma dificuldade de elaboração da castração oral devido justamente a uma dificuldade materna de sustentá-la.

Como nos lembra Dolto (1984, p. 79) "o desmame, esta castração oral do bebê, implica que a mãe também aceite a ruptura do corpo-a-corpo em que a criança se encontrava, passando do seio interno aos seios aleitadores e ao regaço, totalmente dependente da presença física dela. Esta castração oral da mãe implica que ela mesma seja capaz de se comunicar com seu filho de outra forma que não lhe dando alimento, lidando com seus excrementos e devorando-o com beijos e carícias: através de palavras e gestos que também são linguagens." A dependência de Renato do corpo de sua mãe parece encontrar apoio e reforço na extrema dependência de Lúcia ao corpo de seu filho; tal reciprocidade talvez tenha atrelado demasiadamente esses dois corpos, dificultando a Renato a busca de diferentes modalidades de prazer e trocas com o exterior.

O lugar ocupado por um filho na subjetividade materna pode ser melhor compreendido se nos remetermos ao desenvolvimento sexual e edípico desta mãe. Não pretendo aqui fazer uma construção do que poderia ter sido a travessia do Édipo em Lúcia, pretendo apenas frisar e lembrar ao leitor a relação do percursso edípico materno com o desenvolvimento psíquico do filho. Sabemos desde Freud ${ }^{4}$ que uma das "saídas" do Complexo de Édipo na menina é a instauração de uma equivalência simbólica entre pênis e criança. Desta forma, a criança é para a mãe o objeto do seu desejo infantil inconsciente - o falo. Ele é o significante da falta. A criança identifica-se imaginariamente com o objeto de desejo materno, pois deseja ser desejada pela mãe. É este encontro de desejos mãe/criança que constitui o narcisismo: mãe-fálica (célula narcísica). A criança torna-se o desejo materno ao identificar-se imaginariamente com ele. É a entrada do pai nesta díade imaginária mãe-criança que possibilitará que a criança saia da captação imaginária, ou seja, escape da identificação com o objeto de desejo da mãe. No entanto, a tríade só se instaurará se a mãe puder buscar a satisfação de seu desejo em outro lugar que não exclusivamente o filho. Ou seja, se ela for capaz de reconhecer sua castração e investir sua libido em outro lugar fálico. Assim, a possibilidade da castração no filho depende, primeiramente, de uma aceitação da castração na mãe pois é 
somente aceitando-se castrada que a mãe dará lugar ao pai. ${ }^{5} \mathrm{Na}$ relação Lúcia-Renato, este parece submerso no desejo materno. O lugar ocupado por Renato e a ele delegado por Lúcia parece evidenciar uma dificuldade desta em reconhecer-se castrada, desejante e faltante. Colocando Renato como um obturador de sua falta, cujo reconhecimento é demasiado dolorido, Lúcia fica impedida de acompanhá-lo nas suas próprias castrações simbolígenas, tão fundamentais para seu desenvolvimento psíquico.

Neste sentido, este caso é revelador da importância conferida à escuta da mãe paralelamente ao atendimento da criança. Sendo ela a principal agente das castrações pelas quais o filho deverá passar, aquilo que a impede de sustentá-las, ou o modo "capenga" como ela as sustenta, deve ser trabalhado e elaborado em um espaço analítico.

Em relação ao trabalho terapêutico com a própria criança, podemos dizer que escutar e acompanhar analiticamente uma criança com distúrbios em sua imagem corporal pode significar falar-lhe segundo as imagens do corpo em jogo. Como conclui Nasio (1991, p.17): "o trabalho analítico com crianças consiste em uma mútua confrontação não somente de lugares, mas também de velocidades, dos ritmos e fundamentalmente das imagens do corpo. Isto é, o analista opera enredando e entremeando suas próprias imagens do corpo com as imagens do corpo da criança. Quando você considera o trabalho do psicanalista como decodificação da imagem do corpo (...), (trata-se) de falar inconscientemente, através da imagem do seu próprio corpo, o mesmo código implícito na imagem do seu próprio corpo, o mesmo código que o implícito na imagem do corpo da criança."

Neste sentido podemos evocar algumas vivências de Renato ocorridas durante seu atendimento. Em uma sessão, por volta do segundo mês de atendimento, Renato corta sua mão no vidro da janela da sala e, sem emitir nenhuma manifestação de dor, passa várias vezes a mão sangrando na boca. Algumas sessões mais tarde, Renato vê uma grande figura de mão em uma revista e ri copiosamente; desde então torna-se frequente a procura de Renato por esta figura nas sessões seguintes. A ausência da manifestação de dor em Renato, ou melhor, sua aparente indiferença ao fato, parece sugerir uma falha no processamento do que Dolto nomeia de castração anal, através da qual a criança passaria a reconhecer-se como um corpo autônomo, passível de machucar-se e ser machucado por outros.

A partir daí aparece recorrentemente o interesse de Renato por suas mãos, entrelaçando-as, colocando-as em cima de uma folha de papel e olhando muito para elas como um bebê em suas primeiras explorações.

Nesse momento do atendimento acrescento à caixa lúdica de Renato um conjunto de sete pranchas de madeira de "conceito corporal" que fazem menção a algumas partes do corpo. Por volta do sexto mês de atendimento, Renato interessa-se pelas pranchas do pé e da mão. Monta, sem dificuldades, os dedos no pé e tenta fazer o mesmo com a mão. Não conseguindo montá-la, pega a mão inteira de madeira e entrelaçaa com seus dedos, em seguida brinca, deitado, com ela no chão. Coloca, então, a minha mão no chão de modo a cobrir a mão de madeira. Retorna, então, ao pé de madeira, colocando o meu pé sobre ele e depois, bravo, o retira e o recoloca na prancha a que pertence. Desmonta, então, os dedos do pé e fica bravo por não conseguir montá-lo novamente. Proponho ajudálo com a montagem do pé, mas ele recusa. Renato atém-se, pela segunda vez 
em todo o atendimento, à famíla de pano, brincando em dispor seus membros de variadas maneiras: o pai e o bebê, a enfermeira e o bebê, e o gato no meio do casal. A meu ver, poderíamos considerar esta sessão como um "turning point" no processo terapêutico de Renato: foi a partir de uma vivência constante de percepção de partes do corpo de madeira, do seu e do meu corpo que lhe foi possivel uma aproximação mais detida da familia de pano, momento, inclusive, em que pôde aparecer uma triangularidade (casal e gato de panos) em uma dinâmica até então dual.

Nas sessões seguintes, é frequente a procura de Renato, tanto pelas peças das pranchas de conceito corporal como também pelas minhas mãos e pés. Durante uma delas, por volta de cinco meses após o episódio do corte da mão, Renato pega as pranchas e, ao ver a da mão, fala: "ai, ai" e então brinca de fechar a caixa lúdica no dedo falando novamente "ai, ai" e fingindo chorar. Abre e fecha a caixa pela última vez dizendo "mamãe"e "mamão". Ao ouvir um barulho de ônibus, corre para a janela e, olhando para fora, diz "bebê" seguidas vezes. Escrevo na lousa: mãe, mão e bebê, Renato ri muito repetindo "bebê, bebê", mais tarde "mãe, mão, bêbe". Digo, nesse momento, "bebê da mamãe", acrescentando que me parecia que sua mãe queria que ele ainda fosse um bebê e que ele ficava muito na dúvida em continuar o bêbe da mamãe ou crescer.

A questão da mão em Renato vai aparecer novamente com muita intensidade em uma sessão nove meses após o episódio do corte de seu dedo na janela. Renato dirige-se ao espelho com seu dedo indicador esticado fingindo chorar para em seguida ir até a janela de vidro ainda chorando. É interessante notar que nesse momento Renato não se gruda a sua imagem no espelho como antigamente, mas aproxima-se dela fazendo caretas, como se já pudesse visualizá-la como algo distinto, separado dele, explorando a relação dela com seu próprio rosto.

Em seguida, Renato aproxima-se de mim e coloca as mãos em cima de uma folha em branco dizendo: "mão". Coloco as minhas mãos em cima da dele dizendo também "mão". Ele então diz: "tira" e nós dois tiramos nossas mãos. Renato pega meu dedo (que eu percebo neste momento que tinha um bandaid!) e, assoprando, diz "ai". Aperta meu dedo e agora sou eu que digo: "ai". Encaminhase para a caixa lúdica e fecha de propósito seu dedo na caixa dizendo "ai", seguidas vezes, e depois retorna à janela ainda se queixando de dor.

Nesse momento convido Renato a desenharmos juntos "dedo machucado", pedindo-lhe que coloque o seu dedo machucado sobre o papel. Ele o faz e então desenho o contorno de seu dedo na folha de papel fazendo em seguida o mesmo com o meu dedo machucado e escrevendo nossos nomes sobre cada um dos desenhos. Como estávamos no término da sessão, peço a folha de papel a Renato, coloco a data e a guardo comigo. Ele fica muito bravo, gritando, ameaçando chorar e batendo seguidamente a cabeça na 
parede. Nesse momento parece que somos os mesmos: o meu dedo e o dedo dele não se diferenciam. Talvez uma conduta terapêutica interessante poderia ter sido cortar a folha de papel em dois, dando-lhe o "seu dedo machucado" e eu permanecendo com o "meu dedo machucado".

A sugestão do desenho surgiu como uma tentativa de fornecer a Renato uma possibilidade de simbolização: desenhando o dedo, tomando posse de uma representação, de algo que fizesse uma alusão ao dedo machucado, talvez Renato pudesse perceber seu dedo real como separado e distinto do meu, deixando de viver uma dor que não lhe pertencia. Poderíamos ainda pensar que essa dor vivida por Renato e sustentada no meu dedo machucado remete a uma outra dor: a uma dor em Lúcia. Lembremo-nos da conexão, em suas associações, entre "mãe e mão".

\section{CONSIDERAÇÕES FINAIS}

Se nos remetermos à época em que Renato começou o tratamento no Lugar de Vida, observamos que meu corpo não era investido por ele: seu olhar me perpassava, não olhava para mim, não se dirigia a mim quando eu o chamava - agora me olha, me toca. É visível que houve um investimento de Renato no meu corpo, mas antes de tudo houve um oferecimento do meu corpo para ele, que ele teve a oportunidade de utilizá-lo como espelho e suporte de suas representaçôes corporais. O que vemos aqui é o lugar e importância do corpo do analista em tratamento de casos como esse. Esta entidade por nós denominadas de "corpo do analista", e que deve ser mais propriamente denominada, como nos alerta Dolto, de "imagem do corpo do analista", aparece no tratamento como o suporte, o lugar de consolidação da transferência. É através dela que o jogo de espelhamento e reconhecimento do outro e de si mesmo se revela, possibilitando que o analista (aquele que é permeável a sua própria imagem de corpo) a utilize na formulação, tanto de suas intervenções verbais quanto naquelas exclusivamente corporais.

Se, como diz Dolto, a imagem corporal se constitui através das diversas castrações pelas quais passa o sujeito, na história de Renato poderíamos dizer que houve "ausência de castração". Com isto quero dizer que elas não operaram ali onde eram chamadas: no momento do desmame oral e da castração anal. Assim, este corpo de Renato não pode ser imaginado e atuado como um corpo separado, independente e autônomo; ele precisou permanecer como um corpo-objeto-biológico que necessita de cuidado e atenção constantes. A escuta oferecida a Lúcia visa possibilitar um outro posicionamento desta frente a Renato, capacitando-a a prescindir de seu filho como um corpo-objeto-narcísico e a acompanhar seu filho nas castrações que lhe são tão necessárias e constitutivas. 


\section{REFERÊNCIAS BIBLIOGRÁFICAS}

AULAGNIER, P. (1990). Um intérprete em busca de sentido. São Paulo: Escuta.

BRAUER, F. J. (1994). A criança no discurso do Outro. São Paulo: Iluminuras.

DOLTO, F. (1992). A Imagem inconsciente do corpo. São Paulo: Perspectiva.

DOLTO, F. \& NASIO, J-D. (1991). A Criança do espelbo. Porto Alegre: Artes Médicas.

DOR, J. (1992). Introdução à leitura de Lacan. Porto Alegre: Artes Médicas.

FREUD, S. (1974 a) As pulsões e seus destinos. In: Obras Psicológicas Completas. ESB. Rio de Janeiro: Imago Editora, v. XIV. [1915]

(1974 b) Três ensaios sobre a sexualidade. In: Obras Psicológicas Completas. ESB. Rio de Janeiro: Imago Editora, v. VII. [1905]

GARCIA-ROSA, L.A. (1986). Acaso e repetição em Psicanálise. Rio de Janeiro: Zahar.

(1984). Freud e o inconsciente. Rio de Janeiro: Zahar. (1990). O mal radical em Freud. Rio de Janeiro: Zahar.

LAPLANCHE, J. \& PONTALIS, J.B. (1982). Vocabulário da Psicanálise. São Paulo: Martins Fontes. [1967]
LAZNIK- PENOT, M.-C. (1991). O que a clinica do autismo pode ensinar aos psicanalistas. Salvador: Álgama.

LECLAIRE, S. (1992). Corpo erógeno. São Paulo: Escuta.

LEFORT, R. e R. (1994). Nascimento do outro: duas psicanálises. Salvador: Fator.

MACEDO, H. O. DE. (1983). Ana K. ou a conjugação do corpo: bistória de uma análise. Rio de Janeiro: Francisco Alves.

OLIVEIRA, ALMEIDA \& OLIVEIRA. (1995). Imagem inconsciente do Outro - a encarnação simbólica do sujeito desejante. Boletim de Novidades. Pulsional, ano VIII, n. 69. Escuta.

PANKOW, G. (1969). O Homem e sua Psicose. Campinas: Papirus.

ROSENBERG, A. M. D. (1994). O lugar dos pais na psicanálise de crianças. São Paulo: Escuta.

SOUZA FILHO, A. (org.) (1988). A clínica da psicose. Campinas: Papirus.

VOLNOVICH, J. (1993). A psicose na infância. Rio de Janeiro: Relume Dumará. 


\section{NOTAS}

$1 \mathrm{O}$ atendimento da criança em questão foi conduzido durante o estágio realizado pela autora no quadro do curso de aperfeiçamento "Tratamento e Escolarização de Crianças com Distúrbios Globais de Desenvolvimento", do Instituto de Psicologia da USP, e supervisionado por Jussara Falek Brauer.

2 A questão da pulsão e do instinto tem sido vastamente trabalhada por Freud e seus comentadores. Não é meu interesse aqui explorar mais detalhadamente estes conceitos. Remeto o leitor interessado aos próprios textos de Freud, em especial Os três ensaios sobre a sexualidade (1974b) e a Pulsão e suas vicissitudes (1974a) onde figuram a gênese e desenvolvimento dos quatro componentes da pulsão. Para comentários sobre o tema, recomendo Garcia Rosa, L.A. Acaso e Repetição em Psicanálise (1989), Freud e o Inconsciente (1988) e Laplanche, J. \& Pontalis, J. O Vocabulário de Psicanálise (1982).

3 É característica de Dolto a utilização de formulações freudianas, lacanianas, ou como vemos neste caso, winnicotianas de forma inovadora e particular, sem o cuidado, no entanto, de explicitar as modificações conceituais que realiza. Dolto empresta o termo "objeto transicional" forjado por Winnicott como um objeto privilegiado pela criança em um determinado momento de desenvolvimento cuja função é a de situar-se em um espaço de transição entre a mãe real e a sua representação interna para a criança e o coloca no campo da linguagem desta dupla.

${ }^{4}$ Cf. Freud, S. (1974) A dissolução do Complexo de Edipo. In: Obras Psicológicas Completas, v. XIX. Rio de Janeiro: Ed. Imago. [1924]

5 Para maiores esclarecimentos sobre a questão edípica materna e sua relação com a psicose, ver: "A função da mãe- a Clinica das Psicoses" de Checchinato, D. e "Complejo de Edipo - El Edipo y la Clínica Freudiana" de Abasz e colaboradores. 